\title{
New business models for research and development with affordability requirements are needed to achieve fair pricing of medicines
}

\author{
For research and development to systematically deliver fairly priced medicines, new approaches \\ to financing and organisation are needed, and affordability must be integrated into push, pull, and \\ pooling mechanisms, say Fatima Suleman and colleagues
}

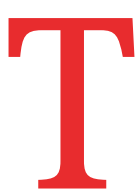
he health of populations depends, in part, on the development and appropriate use of new drugs, diagnostics, vaccines, and other biological medicines (broadly referred to as medicines). ${ }^{1}$ Realising the social value of pharmaceutical innovation, however, is difficult. Policies must promote investment in research and development in areas of significant unmet health need while also ensuring access to resulting innovations. ${ }^{2}$

Pharmaceutical $R \& D$ relies heavily on the monopoly pricing enabled by patents or other forms of market exclusivity. This threatens the goals of innovation and access and can result in "unfair" prices. ${ }^{2}$ A fair price for medicines is one that is affordable for health systems and patients while providing sufficient market incentive for industry to invest. ${ }^{3}$

Concerns about the high and rising prices of new medicines ${ }^{4}$ have prompted increased interest in the possibility that changing the way in which R\&D is financed and organised might result in fairer prices

\section{REY MESSAGES}

- Governments and other research funders remain slow to invest in alternative research and development models, though the need is well recognised

- Governments and other research funders should insist on binding affordability requirements as a condition of all research and development funding to ensure fair pricing of medicines

- Governments and other research funders should invest in models that delink the cost of research and development from the cost of production, and invest in research that measures the efficiency of such alternative models for innovative medicines. In particular, "delinkage," where the financing of R\&D is decoupled from the price of medicines by removing market exclusivity as a driving incentive, has attracted growing attention as an alternative business model for pharmaceutical R\&D. This idea was recently endorsed in the political declaration of the United Nations high level meeting on tuberculosis.

The range of policy tools that can facilitate fair pricing falls into three broad categories: (1) "push" mechanisms, which typically provide grants for research projects in advance; (2) "pull” mechanisms, which provide rewards for research accomplishments at various stages of the drug development process; and (3) "pooling" mechanisms, which facilitate access to knowledge to advance scientific progress, thereby shortening timelines and reducing development costs. Below we provide an overview of these mechanisms and argue that without adequately enforced affordability requirements they may not lead to fair pricing.

\section{Push mechanisms}

Push mechanisms offer direct funding for various stages of drug R\&D projects in advance, usually in the form of grants. These payments can incentivise (push) research by product developers when there is an unmet need but limited commercial potential or a high risk of failure. ${ }^{46}$

Conditions tied to R\&D grants can include requirements that product developers price the resulting medicines affordably. A patented technology may be transferred to a body other than the grant recipient-for example, an academic institution may grant licences to a private company. In such cases, funders can require the grant recipient to include affordability guarantees in any such agreements.

By subsidising the costs of $R \& D$, grant funding reduces the need for developers to recoup investments through higher prices. ${ }^{7}$ For neglected diseases or other recognised areas of market failure, public or philanthropic funding accounts for all or nearly all the direct costs of R\&D. ${ }^{8}$ In these cases, charging the lowest sustainable prices for medicines is a reasonable expectation.

Traditionally, product development at a later stage has been financed by the pharmaceutical industry responding to pull incentives, with no pricing conditions attached. An exception, however, is neglected diseases, for which public or philanthropic grants have financed late stage product development. These often come with affordability requirements. Such grants are increasingly being considered for new antibiotics, medicines needed for disease outbreaks, and some paediatric formulations.

Early stage research is largely funded through public grants. Early stage grants from the US National Institutes for Health (NIH), the world's single largest funder of biomedical research, give the funder the right to "march in" and take control of intellectual property if medicines are not made available on "reasonable terms." The $\mathrm{NIH}$, however, has never made use of this right, despite repeated petitions asking it to do so in response to high medicine prices. ${ }^{9}$

There is some evidence that push mechanisms can steer investments, reduce barriers to entry by small and medium sized enterprises, and absorb early stage risks of failure. ${ }^{10}$ A disadvantage of push mechanisms is the incentive for developers to oversell investments in their particular projects. ${ }^{811}$ Push mechanisms may also create a tension between the desire to steer investments and giving developers insufficient flexibility to be 
efficient and innovative in their research. Without adequate enforceable affordability requirements push incentives will not lead to fair prices.

\section{Pull mechanisms}

Pull mechanisms deliver rewards after a research and development objective or milestone is reached. These rewards may include incentives such as tax breaks, cash prizes, patents or data exclusivity, or advance market commitments where procurers commit to buy a certain amount of medicines. In contrast to push mechanisms, pull incentives based on outcome only compensate successful achievement of milestones or end products meeting specific criteria.

Pull mechanisms can contribute to fair pricing if the rewards are designed to do so, but this has not generally been the case. To date, most pull mechanisms have aimed at promoting innovation but not affordability. For example, the US priority review voucher programme provides a tradeable voucher as a reward for priority Food and Drug Administration review of a potentially lucrative medicine for a neglected or outbreak prone disease. The programme, however, does not require the voucher recipient to set affordable prices or to supply the relevant medicine to the market. $^{12}$

In addition, not all pull mechanisms are compatible with achieving affordability goals. Monopolies, whether based on patents or data exclusivity, enable a company to price the product at relatively high levels for a certain period. Furthermore, policy makers have sometimes even declined to include affordability requirements in pull mechanisms, as in the case of the priority review voucher. Some of these mechanisms have been criticised for "socialising the risks and privatising the profits" ${ }^{13}$ of the drug development process.

Nevertheless, it is possible to craft some pull incentives to promote affordability. For example, large scale prizes, such as the antibiotics prize fund proposed in the US, ${ }^{14}$ would reward inventors of new medicines; in exchange, the inventor would relinquish their patent monopoly and allow new medicines to be sold close to the cost of production.

Because developers bear the development costs in advance, pull mechanisms provide a greater incentive to maximise efficiency and innovation than push mechanisms. ${ }^{9}$ One disadvantage is that the financial risk and uncertainty inherent in pull mechanisms may deter participation. This is particularly true for smaller companies that may lack the resources to finance lengthy R\&D processes. Other challenges include determining the size of the incentive needed to motivate developers while remaining cost effective, and defining drug characteristics linked to the pull incentive that are neither too specific nor too general. Finally, an effective outcome based pull system relies on a funder that will credibly commit to long term funding guarantees. ${ }^{15}$

\section{Pooling mechanisms}

Information sharing through the pooling of data or intellectual property can expedite innovation by removing the barriers to $R \& D$ created by secrecy, patents, and data exclusivity, and by minimising wasteful duplication of effort. By doing so, pooling can lower the cost of innovation and thereby enable more affordable pricing. For example, the Medicines Patent Pool, established in 2010 with support from Unitaid, pools patents relating to medicines for HIV/AIDS, hepatitis $\mathrm{C}$, and tuberculosis. This accelerates the development of fixed dose combinations and facilitates testing of multiple drugs together to develop regimens rather than individual molecules.

Data pooling is being promoted through open source innovation initiatives, in which interested stakeholders place knowledge, data, and technology in the public domain. A number of open initiatives are in operation, including the Indian Open Source Drug Discovery initiative, the Librassay initiative, and the WIPO Re:Search consortium. All these allow scientists to share information and access intellectual property to search for new treatments.

The central idea behind these initiatives is that open collaboration and exchange of information will both expedite, and lower the cost of, the development of desired innovations, leading to more affordable prices. It should be noted, however, that specific enforceable conditions requiring fair pricing are needed to ensure that lower costs do indeed result in lower prices, rather than just producing wider profit margins.

\section{Discussion}

Strategic use of push, pull, and knowledge pooling mechanisms can build affordability into the R\&D process. Existing push mechanisms generally function well and enjoy wide support, but more must be done to ensure that medicines resulting from such push funding are fairly priced. This includes ensuring strong pricing and access provisions in funding agreements, and better enforcement of such provisions that already exist.

Interest in pull mechanisms or those that combine push and pull has risen in recent years. According to a recent mapping exercise, at least 49 alternative $R \& D$ funding initiatives are in operation, and 32 are being planned. ${ }^{4}$ However, many alternative models remain underused and insufficiently tested by governments and other research funders. These include prize funds, advance purchase agreements, patent buy-outs, innovative taxes, conditional licences, and pricing guarantees.

Implementing alternative $R \& D$ models requires new sources of financing, particularly when the use of high prices and market exclusivities as drivers of R\&D investments are deliberately limited. Because alternative R\&D business models have largely been employed in areas of market failure, the financing has come from public and philanthropic sources. For example, most of the funding for research into neglected disease (if the $\mathrm{NIH}$ is excluded) comes from the two largest philanthropic investors-namely, the Bill and Melinda Gates Foundation and the Wellcome Trust. Together they contributed \$660m (£520m; €580m) in $2014 .^{16}$

A wide variety of both state and nonstate actors also contribute significantly to alternative funding mechanisms for dealing with neglected diseases, antimicrobial resistance, and diseases with epidemic potential. However, compared with the estimated US $\$ 240 \mathrm{bn}$ spent on biomedical R\&D annually, investment in alternative business models is a drop in the ocean, probably $<1 \%$ of total investment. Efforts to build affordable prices into the R\&D process itself remain the exception to the rule. ${ }^{1718}$

Thus an important question is whether existing examples can be replicated or scaled up. This would ensure that R\&D activities systematically result in affordably priced medicines for a broader set of diseases and public health challenges, beyond the handful of areas recognised as market failures. An intriguing example has been provided by the Drugs for Neglected Diseases project to develop an affordable hepatitis $\mathrm{C}$ drug. The first clinical trial results were highly promising. If successful, the medicine could be sold for less than \$300 per treatment course, compared 
with $\$ 12500$ to $\$ 100000$ for hepatitis C drugs in the same class developed through traditional models. ${ }^{19}$

A key barrier to replication of such efforts and to testing of alternative innovation models is a lack of funding. Some WHO member states have supported the creation of a fund housed at the Special Programme for Research and Training in Tropical Diseases, hosted at WHO. They propose a voluntary financing model based on the principles of delinkage, the use of open knowledge innovation, and open licensing for access. ${ }^{20}{ }^{21}$ None of these proposals has attracted major financial support, underlining the general difficulty in generating funding for such initiatives. Significant sums have been mobilised, however, to deal with R\&D for antimicrobial resistance and epidemic threats, suggesting that it is feasible. ${ }^{16}$

It is also notable that political will is not always present. In WHO and UN processes, some influential countries have not supported promotion of alternative R\&D models that may challenge the dominant market exclusivity based system.

\section{Conclusion}

Consensus for alternatives to the status quo is growing, ${ }^{22}$ and calls for reform are becoming more insistent. ${ }^{2}$ Health systems have never been so financially challenged, partly because the demands on them have never been so great as many drive towards universal health coverage. Meanwhile, the demographic and epidemiological transformation of global populations continues rapidly, with a seemingly inexorable increase in non-communicable disease and the looming threat of generalised antimicrobial resistance. ${ }^{23}$

The potential of alternative models to facilitate more efficient $R \& D$ and lower prices is now widely recognised. It is now up to states and other funders of research to insist upon affordability requirements in all R\&D funding, to enforce them, and to increase investment in alternative models.

Contributors and sources:FS drafted the article and finalised it with contributions from ML, SM, and SGM, who provided input and critical feedback for important intellectual content. FS is the guarantor. This manuscript is based on a narrative review of the literature and the authors' experience and expertise in working in pharmaceutical policy, pricing, and reimbursement in different settings worldwide.
Competing interests: We have read and understood BMJ policy on declaration of interests and have no relevant interests to declare.

Provenance and peer review: Commissioned; externally peer reviewed.

This article is part of a series proposed by $\mathrm{WHO}$ and commissioned by The BMJ. The BM/ retained full editorial control over external peer review, editing, and publication of these articles. Open access fees are funded by WHO.

Fatima Suleman, professor ${ }^{1,2}$

Marcus Low, postgraduate student ${ }^{2}$

Suerie Moon, director of research ${ }^{3}$

Steven G Morgan, professor ${ }^{4}$

${ }^{1}$ Prince Claus Chair of Development and Equity, Affordable (Bio) Therapeutics for Public Health, Utrecht University, Netherlands

${ }^{2}$ Discipline of Pharmaceutical Sciences, School of Health Sciences, University of KwaZulu-Natal, Durban, South Africa

${ }^{3}$ Global Health Centre, Graduate Institute of International and Development Studies, Geneva, Switzerland

${ }^{4}$ School of Population in Public Health, University of British Columbia, Vancouver, Canada

Correspondence to: FSuleman sulemanf@ukzn.ac.za

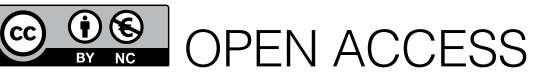

This is an Open Access article distributed under the terms of the Creative Commons Attribution IGO License (https://creativecommons.org/licenses/ by-nc/3.0/igo/), which permits use, distribution, and reproduction for non-commercial purposes in any medium, provided the original work is properly cited.

\section{Check for updates}

1 Morgan S, Lopert R, Greyson D. Toward a definition of pharmaceutical innovation. Open Med 2008;2:e4-7.

2 United Nations Secretary-General's High-level Panel on Access to Medicines. Promoting innovation and access to health technologies. United Nations Development Programme, 2016.

3 World Health Organization. Essential medicines and health products. 2017. https://www.who.int/ medicines/access/fair_pricing/en/

4 Kiddell-Monroe R, Greenberg A, Basey M. Re:Route: a map of the alternative biomedical R\&D landscape. Universities Allied for Essential Medicines, 2016. http://www.altreroute.com/assets/download/UAEM Reroute_Report.pdf

5 United Nations. Political declaration of the United Nations high-level meeting on tuberculosis. 2018. https://www.un.org/pga/72/wp-content/uploads/ sites/51/2018/09/Co-facilitators-Revisedtext-Political-Declaraion-on-the-Fight-againstTuberculosis.pdf

6 Novartis. Novartis expands partnership with Medicines for Malaria Venture to develop nextgeneration antimalarial treatment. 2016. https:// www.iol.co.za/business-report/companies/novartisexpands-malaria-research-2034875

7 GSK. First African country introduces GSK's pneumococcal vaccine through innovative financing mechanism. 2011. https://www.gsk.com/en-gb/ media/press-releases/first-african-countryintroduces-gsk-s-pneumococcal-vaccine-throughinnovative-financing-mechanism/

8 Policy Cures Research. Neglected disease research and development: reflecting on a decade of global investment. G-FINDER Report, 2017. https://www. policycuresresearch.org/g-finder-2017/

9 Treasure CL, Avorn J, Kesselheim AS. What is the public's right to access medical discoveries based on federally funded research?JAMA 2014;311:907-8. doi:10.1001/jama.2014.404

10 Spellberg B, Sharma P, Rex JH. The critical impact of time discounting on economic incentives to overcome the antibiotic market failure. Nat Rev Drug Discov 2012;11:168. doi:10.1038/nrd3560-c1

11 Mossialos E, Morel CM, Edwards S, Berenson J, Gemmill-Toyama M, Brogan D. Policies and incentives for promoting innovation in antibiotic research. European Observatory on Health Systems and Policies, 2010. http://www.euro.who.int/_data/ assets/pdf_file/0011/120143/E94241.pdf

12 Vouching for access. Nat Med 2016;22:693. doi:10.1038/nm.4151

13 Derber C. Marx's ghost: midnight conversations on changing the world. Routledge, 2016.

14 S.771-Improving Access To Affordable Prescription Drugs Act. 115th Congress, 2017-18. https://www. congress.gov/bill/115th-congress/senate-bill/771.

15 Renwick MJ, Brogan DM, Mossialos E. A systematic review and critical assessment of incentive strategies for discovery and development of novel antibiotics. / Antibio (Tokyo) 2016;69:73-88. doi:10.1038/ja.2015.98

16 Policy Cures. Neglected disease research and development: the Ebola effect. G-FINDER Report, 2015. http://www.policycures.org/downloads/ Y8\%20GFINDER\%20full\%20report\%20web.pdf

17 Decision of the 67th World Health Assembly, WHA67.15. In: Sixty-seventh World Health Assembly, Geneva, 19-24 May 2014. World Health Organization, 2014. http://apps.who.int/gb/ebwha/ pdf_files/WHA67-REC1/A67_2014_REC1-en.pdf

18 Balasegaram M, Bréchot C, Farrar J, et al. A global biomedical R\&D fund and mechanism for innovations of public health importance. PLoS Med 2015;12:e1001831. doi:10.1371/journal. pmed.1001831

19 Kollewe J. Non-profit's $\$ 300$ hepatitis C cure as effective as $\$ 84000$ alternative. Guardian $2018 \mathrm{Apr}$ 12. https://www.theguardian.com/science/2018/ apr/12/non-profits-300-hepatitis-c-cure-aseffective-as-84000-alternative

20 World Health Assembly. Follow-up of the report on the Consultative Expert Working Group on Research and Development: financing and coordination. WHO, 2014. http://apps.who.int/gb/ebwha/pdf_files/ WHA67/A67_28Add1-en.pdf

21 Røttingen JA, Chamas C, Goyal LC, Harb H, Lagrada L, Mayosi BM. Securing the public good of health research and development for developing countries. Bull World Health Organ 2012:90:398-400. doi:10.2471/BLT.12.105460

22 Wirtz VJ, Hogerzeil HV, Gray AL, et al. Essential medicines for universal health coverage. Lancet2017;389:403-76. doi:10.1016/ S0140-6736(16)31599-9

23 Chan M. Remarks at the $\mathrm{G} 7$ health ministers meeting Antimicrobial resistance: realizing the "one health" approach. Berlin, Germany. 8 October 2015. https:// www.who.int/dg/speeches/2015/g7-antimicrobialresistance/en/

Cite this as: BMJ 2020;368:14408 http://dx.doi.org/10.1136/bmj.l4408 